\title{
Gambling Behaviour and Psychosocial Correlates among University Students in 23 Low, Middle and Emerging Economy Countries
}

\author{
Karl Peltzer \\ ASEAN Institute for Health Development, Madidol University, Salaya, Phutthamonthon, Nakhonpathom, Thailand, 73170, \\ University of Limpopo, Turfloop Campus, Sovenga 0727, South Africa, HIV/AIDS/STIs/and TB (HAST), \\ Human Sciences Research Council, Private Bag X41, Pretoria 0001, South Africa \\ Supa Pengpid \\ ASEAN Institute for Health Development, Madidol University, Salaya, Phutthamonthon, Nakhonpathom, \\ Thailand, 73170, University of Limpopo, Turfloop Campus, Sovenga 0727, South Africa \\ Email:supaprom@yahoo.com
}

\section{Doi:10.5901/mjss.2014.v5n27p1086}

\section{Abstract}

The aim of this study was to investigate gambling behaviour and psychosocial correlates among university students from 23 low and middle income and emerging economy countries. Using anonymous questionnaires, data were collected from 17789 university students, $41.7 \%$ men and $58.3 \%$ women, with a mean age of 20.9 years $(S D=2.9)$, from 23 countries across Africa, Asia and Americas. Overall, 27.1\% reported gambling less than once a week and $8.4 \%$ once a week or more; $13.9 \%$ in men and $4.4 \%$ in women. Multivariate logistic regression found that male gender, residing in a low or lower middle income country, having been in a physical fight, tobacco use, not always driving within the speed limit, sexual risk behaviour, depression and PTSD symptoms were associated with frequent gambling. Several clustering risk behaviours were identified which can be utilized gambling prevention approaches.

Keywords: Gambling behaviour; Psychosocial correlates; University students; Multi-country

\section{Introduction}

"Gambling is understood as the established practice of staking money or other valuables on games or events of an uncertain outcome." (Binde, 2005, p.3) Young people including university students are a high risk group for gambling problems (Moore et al., 2013). A high prevalence of gambling participation and problem gambling has been found in different university student populations, mainly in studies in high income countries (Etel, Tabchi, Bou Khalil, Hlais \& Richa, 2013; McComb \& Hanson, 2009; Mubaraka \& Blanksbya, 2013; Tozzi, Akre, Fleury-Schubert \& Suris, 2013). University students engage in a wide range of gambling behaviours, including playing the lottery, poker/cards for money, casino games (i.e., slots/poker machines), horse racing, betting on sports and internet gambling (Burger, Dahlgren, \& MacDonald, 2006; Engwall et al., 2004; McComb \& Hanson, 2009; Moore et al., 2013).

Factors associated with gambling participation, non-problem gambling, and/or problem gambling include 1) sociodemographic variables such as male gender (Gray, 2004; Moore et al., 2013), older age (Tozzi et al., 2013), monthly income (Winters, Bengston, Dorr \& Stinchfield, 1998), 2) other risk behaviour, including substance use, drinking, smoking, drug abuse (Engwall et al., 2004; Hodgins \& Racicot, 2013; Lorains, Cowlishaw \& Thomas, 2011; Sharp, Dellis, Hofmeyr, Kincaid \& Ross, 2014; Tozzi et al., 2013), delinquency/illegal acts (Johansson et al., 2009), sexual risk behaviour (Huang, Jacobs, Derevensky, Gupta \& Paskus, 2007), and 3) poor mental health, anxiety and mood disorders (Lorains et al., 2011; Moore et al., 2013; Sharp et al., 2014).

The aim of this study was to investigate gambling behaviour and psychosocial correlates among university students from 23 low and middle income and emerging economy countries.

\section{Methods}

\subsection{Participants and procedures}

This cross-sectional study was carried out with a network of collaborators in participating countries (see 
Acknowledgments). The anonymous, self-administered questionnaire used for data collection was developed in English, then translated and back-translated into languages (Arabic, Bahasa, French, Lao, Russian, Spanish, Thai, Turkish) of the participating countries. The study was initiated through personal academic contacts of the principal investigators. These collaborators arranged for data to be collected from intended 400 male and 400 female undergraduate university students aged 16-30 years by trained research assistants in 2013 in one or two universities in their respective countries. The universities involved were located in the capital cities or other major cities in the participating countries. Research assistants working in the participating universities asked classes of undergraduate students to complete the questionnaire at the end of a teaching class. Classes were recruited according to timetable scheduling using stratified random sampling. The students who completed the survey varied in the number of years for which they had attended the university. A variety of majors were involved, including education, humanities and arts, social sciences, business and law, science, engineering, manufacturing and construction, agriculture, health and welfare and services. Informed consent was obtained from participating students, and the study was conducted in 2013. Participation rates were in most countries over $90 \%$. Ethics approvals were obtained from institutional review boards from all participating institutions.

\subsection{Measures}

2.3 Gambling behaviour was assessed with the South Oaks Gambling Screen (SOGS), a standardized measure of pathological gambling and gambling behaviours in their lifetime (Lesieur \& Blume, 1987) was used to assess 9 different gambling behaviours, e.g. "Played cards for money." Response options ranged from 1=not at all to 3=Once a week or more. Cronbach alpha for this 9 item scale was 0.90 in this sample.

2.4 Socio-demographic questions included age, gender, and socioeconomic background were assessed by rating their family background as wealthy (within the highest $25 \%$ in "country", in terms of wealth), quite well off (within the $50 \%$ to $75 \%$ range for their country), not very well off (within the $25 \%$ to $50 \%$ range from "country"), or quite poor (within the lowest $25 \%$ in their country, in terms of wealth) (Wardle \& Steptoe, 1991). We subsequently divided the students into poorer (not very well off and quite poor) and wealthier (wealthy, quite well off) categories.

\subsection{Risk behaviour}

Tobacco use was assessed with the question: Do you currently use one or more of the following tobacco products (cigarettes, snuff, chewing tobacco, cigars, etc.)? Response options were "yes" or "no" (WHO, 1998).

Binge drinking was assessed with one item, "How often do you have (for men) five or more and (for women) four or more drinks on one occasion?" Response options ranged from 1=never to 5=daily or almost daily (Babor, Higgins-Biddle, Saunders \& Monteiro, 2001).

Illicit drug use was assessed with the question, "How often have you taken drugs in the past 12 months; other than prescribed by the health care provider."

Physical fight. For the main outcome, study participants were asked, "During the past 12 months, how many times were you in a physical fight?" Response options ranged from "0 times" to "12 or more times". (CDC, 2013).

Speed limit adherence was assessed with the question, "If you drive a car, do you travel within the speed limit?" Response options ranged from 1=all the time to 4=Little of the time (Wardle \& Steptoe, 1991).

Seat belt use was assessed with the question, "When driving or riding in the front seat of a car do you wear a seat belt?" Response options were, All the time, Some of the time, Never, I don't ride in cars (Wardle \& Steptoe, 1991).

Sexual risk behaviour was assessed with the number of sexual partners in the past 12 months.

\subsection{Poor mental health}

Centers for Epidemiologic Studies Depression Scale (CES-D). We assessed depressive symptoms using the 10-item version of the CES-D (Andresen, Malmgren, Carter \& Patrick, 1994). Scoring is classified from 0-9 as having a mild level of depressive symptoms, 10 to 14 as moderate depressive symptoms, and $\geq 15$ representing severe depressive symptoms (Kilbourne et al., 2002). The Cronbach a reliability coefficient of this 10 -item scale was 0.78 in this study.

Post traumatic stress disorder (PTSD). Breslau's 7-item screener was used to identify PTSD symptoms in the past month (Kimerling et al., 2006). Items asked whether the respondent had experienced difficulties related to a traumatic experience (e.g., "Did you begin to feel more isolated and distant from other people?"). The Cronbach alpha reliability coefficient of this 7 -item scale was 0.75 in this study. 


\section{Data Analysis}

Data analysis was performed using STATA software version 11.0 (Stata Corporation, College Station, Texas, USA). Descriptive statistics were used for reporting the proportion of gambling participation and Pearson Chi-square for gender differences in proportion of frequent gambling. Logistic regression was used to assess the association between sociodemographic variables, risk behaviour, and poor mental health and frequent gambling. Variance inflation factor (VIF) and tolerance values for each model indicate multicollinearity was not a concern in any of the multivariate analyses. Since the study used a clustered design, country was included as a clustering variable in the regression models.

\section{Results}

\subsection{Sample characteristics}

The sample included 17789 university students, $41.7 \%$ men and $58.3 \%$ women, with a mean age of 20.9 years (SD=2.9), from 23 countries across Africa, Asia and Americas. Overall, 27.1\% reported gambling less than once a week and 8.4\% once a week or more; $13.9 \%$ in men and $4.4 \%$ in women. Frequent gambling (once a week or more) was the highest among university students in South Africa (37.0\%), followed by Barbados (19.1\%), Venezuela (16.6\%), Bangladesh (14.2\%), Mauritius (13.4\%), and Turkey (13\%). In all study countries except for India and Ivory Coast male students engaged more often in frequent gambling than female students (see Table 1).

Table 1: Gambling behaviour by country and gender

\begin{tabular}{|c|c|c|c|c|c|c|}
\hline & $\mathrm{N}$ & Gambling less than once a week & \multicolumn{3}{|c|}{ Gambling once a week or more } & $x^{2}$ \\
\hline & & All & All & Men & Women & $<0.001$ \\
\hline All & 17789 & 27.1 & 8.4 & 13.9 & 4.4 & $<0.001$ \\
\hline \multicolumn{7}{|c|}{ Caribbean and South America } \\
\hline Barbados $^{4}$ & 580 & 33.4 & 19.1 & 25.3 & 10.9 & $<0.001$ \\
\hline Grenada $^{3}$ & 418 & 34.0 & 6.4 & 11.3 & 3.8 & 0.002 \\
\hline Jamaica $^{3}$ & 681 & 27.2 & 7.5 & 16.3 & 4.8 & $<0.001$ \\
\hline Colombia $^{3}$ & 727 & 28.3 & 4.7 & 8.6 & 1.5 & $<0.001$ \\
\hline Venezuela $^{3}$ & 551 & 47.9 & 16.6 & 23.5 & 13.6 & $<0.001$ \\
\hline \multicolumn{7}{|c|}{ Sub-Saharan Africa } \\
\hline Cameroon $^{2}$ & 626 & 25.7 & 7.3 & 12.7 & 3.3 & $<0.001$ \\
\hline Ivory Coast ${ }^{2}$ & 745 & 8.4 & 2.2 & 3.2 & 1.2 & 0.057 \\
\hline Madagascar $^{1}$ & 741 & 21.4 & 5.9 & 8.2 & 3.5 & 0.004 \\
\hline Mauritius $^{3}$ & 458 & 35.3 & 13.4 & 31.6 & 5.0 & $<0.001$ \\
\hline Namibia $^{3}$ & 456 & 16.9 & 6.2 & 15.3 & 3.2 & $<0.001$ \\
\hline Nigeria $^{2}$ & 424 & 13.8 & 6.7 & 10.1 & 2.7 & $<0.001$ \\
\hline South Africa ${ }^{3}$ & 588 & 57.1 & 37.0 & 52.7 & 27.8 & $<0.001$ \\
\hline \multicolumn{7}{|c|}{\begin{tabular}{|l|l} 
North Africa, Near East and Central Asia & \\
\end{tabular}} \\
\hline Tunisia $^{3}$ & 797 & 17.3 & 8.5 & 21.2 & 2.3 & $<0.001$ \\
\hline Turkey $^{3}$ & 782 & 42.8 & 13.0 & 22.2 & 3.8 & $<0.001$ \\
\hline Russia $^{3}$ & 789 & 41.7 & 10.9 & 18.1 & 3.9 & $<0.001$ \\
\hline Kyrgyzstan $^{1}$ & 832 & 23.9 & 6.2 & 12.3 & 1.7 & $<0.001$ \\
\hline \multicolumn{7}{|c|}{ South Asia and China } \\
\hline Bangladesh $^{1}$ & 636 & 35.5 & 14.2 & 20.8 & 5.8 & $<0.001$ \\
\hline India ${ }^{2}$ & 788 & 15.1 & 7.5 & 7.9 & 6.6 & 0.487 \\
\hline China $^{3}$ & 1074 & 33.7 & 2.6 & 6.6 & 1.3 & $<0.001$ \\
\hline \multicolumn{7}{|l|}{ Southeast Asia } \\
\hline Laos $^{2}$ & 794 & 23.3 & 4.7 & 10.3 & 1.9 & $<0.001$ \\
\hline Philippines $^{2}$ & 775 & 33.4 & 5.0 & 11.9 & 4.1 & $<0.001$ \\
\hline Singapore $^{4}$ & 876 & 41.9 & 4.5 & 8.0 & 0.9 & $<0.001$ \\
\hline Thailand $^{3}$ & 523 & 47.8 & 10.1 & 15.9 & 8.0 & $<0.001$ \\
\hline
\end{tabular}

1Low income country; 'Lower middle income country; ${ }^{3}$ Upper middle income country; ${ }^{4}$ High income country (Source: World Bank, New Country Classifications, 2013)

\subsection{Type of gambling behaviours}

The type of gambling of less than once a week among university students was most frequently playing cards for money 
$(10 \%)$, followed by played the numbers or bet on lotteries $(8.6 \%)$, played slot machines, poker machines, or other gambling machines (5.9\%) and bet on sport and played bingo (both 5\%), while the four most often gambled frequent gambling activities included played cards for money, bet on sports, bowled, shoot pool, played golf, or played some other game of skill for money, and played slot machines, poker machines, or other gambling machines. Each of the gambling types was more frequently engaged in by men than by women $(P<0.001)$ (see Table 2 ).

Table 2: Frequency of type of gambling behaviours among university students in percent ( $\mathrm{N}=17828)$

\begin{tabular}{|l|c|c|c|c|c|}
\hline & \multicolumn{2}{|c|}{ Frequency of behaviour } & \multicolumn{2}{c|}{$\geq 0$ once a week or more } \\
\hline Gambling activity & $\begin{array}{c}\text { Not at } \\
\text { all }\end{array}$ & $\begin{array}{c}<\text { <once a } \\
\text { week }\end{array}$ & $\begin{array}{c}\geq \text { zonce a week or } \\
\text { more }\end{array}$ & Men & Women \\
\hline Playing cards for money & 87.3 & 10.0 & 2.7 & 4.7 & 1.4 \\
\hline Bet on horses or other animals (off-track betting) & 96.3 & 2.5 & 1.2 & 2.1 & 0.5 \\
\hline Bet on sports & 92.4 & 5.3 & 2.4 & 4.6 & 0.9 \\
\hline Played dice games & 94.3 & 4.0 & 1.6 & 2.8 & 0.8 \\
\hline Went to casino (legal or otherwise) & 93.3 & 5.0 & 1.7 & 2.8 & 1.0 \\
\hline Played the numbers or bet on lotteries & 89.6 & 8.6 & 1.8 & 2.6 & 1.3 \\
\hline Played bingo & 93.1 & 5.3 & 1.6 & 2.4 & 1.0 \\
\hline Played the stock and/or commodities market & 93.9 & 4.5 & 1.6 & 2.5 & 0.9 \\
\hline Played slot machines, poker machines, or other gambling machines & 92.0 & 5.9 & 2.1 & 3.8 & 0.8 \\
\hline Bowled, shot pool, played golf, or played some other game of skill for money & 95.0 & 2.7 & 2.3 & 3.5 & 1.5 \\
\hline
\end{tabular}

\subsection{Associations with frequent gambling}

In univariate analysis, sociodemographic factors (younger age, male gender, coming from a wealthier family background, and residing in a low or lower middle income country), risk behaviours (having been in a physical fight, tobacco use, binge drinking, illicit drug use, not always driving within the speed limit, not always using a seatbelt, and sexual risk behaviour), and poor mental health (depression and PTSD symptoms) were associated with frequent gambling. In multivariate logistic regression analysis, male gender, residing in a low or lower middle income country, having been in a physical fight, tobacco use, not always driving within the speed limit, sexual risk behaviour, depression and PTSD symptoms were associated with frequent gambling (see Table 3).

Table 2: Logistic regression analysis for association between independent variables and frequent gambling

\begin{tabular}{|c|c|c|}
\hline Variables (\%) & Crude Odds ratio $(95 \% \mathrm{Cl})$ & Adjusted Odds ratio (95\% Cl) \\
\hline \multicolumn{3}{|l|}{ Sociodemographics } \\
\hline $\begin{array}{c}\text { Age in years } \\
16-19(32.2 \%) \\
20-21(35.4 \%) \\
22-30(33.4 \%)\end{array}$ & $\begin{array}{c}1.00 \\
1.20(1.06-1.37)^{\star *} \\
1.18(1.03-1.34)^{\star}\end{array}$ & $\begin{array}{c}1.00 \\
1.08(0.87-1.37) \\
1.03(0.79-1.40)\end{array}$ \\
\hline $\begin{array}{c}\text { Gender } \\
\text { Female }(58.3 \%) \\
\text { Male }(41.7 \%)\end{array}$ & $\begin{array}{c}1.00 \\
3.54(3.17-3.94)^{\star \star \star}\end{array}$ & $\begin{array}{c}1.00 \\
2.67(2.17-3.28)^{\star \star \star}\end{array}$ \\
\hline $\begin{array}{c}\text { Family economic background } \\
\text { Quite poor/not very well off }(47.8 \%) \\
\text { Wealthy/quite well-off }(52.2 \%)\end{array}$ & $\begin{array}{c}1.00 \\
1.11(1.00-1.23)^{*}\end{array}$ & $\begin{array}{c}1.00 \\
1.01(0.88-1.14)\end{array}$ \\
\hline $\begin{array}{l}\text { Country income } \\
\text { Low income/Lower middle income (43.2\%) } \\
\text { Upper middle income/High income (56.8\%) }\end{array}$ & $\begin{array}{c}1.00 \\
0.54(0.48-0.60)^{\star \star \star}\end{array}$ & $\begin{array}{c}1.00 \\
0.56(0.41-0.62)^{\star \star \star}\end{array}$ \\
\hline \multicolumn{3}{|l|}{ Risk behaviour } \\
\hline In physical fight (12.4\%) & $2.85(2.52-3.23)^{\star \star \star}$ & $1.91(1.55-2.35)^{\star \star \star}$ \\
\hline Current tobacco use (13.5\%) & $2.57(2.27-2.91)^{\star \star \star}$ & $1.47(1.20-1.80)^{\star \star \star}$ \\
\hline Binge drinking (at least once/month) (13.2\%) & $2.73(2.42-3.07)^{\star \star \star}$ & $1.20(0.98-1.48)$ \\
\hline Illicit drug use (past year) (18.8\%) & $1.38(1.23-1.56)^{\star \star \star}$ & $1.12(0.92-1.38)$ \\
\hline Not always driving within speed limit (65.5\%) & $1.87(1.63-2.15)^{\star \star \star}$ & $1.25(1.02-1.53)^{\star}$ \\
\hline Not always using seatbelt (52.9\%) & $1.22(1.10-1.36)^{\star \star \star}$ & $1.08(0.90-1.29)$ \\
\hline Sexual risk behaviour (two or more sexual partners in past year) (16.8\%) & $3.34(2.96-3.76)^{\star \star *}$ & $1.55(1.27-1.89)^{\star \star \star}$ \\
\hline \multicolumn{3}{|l|}{ Poor mental health } \\
\hline Depression symptoms (severe) (12.2\%) & $1.48(1.29-1.70)^{\star \star \star}$ & $1.30(1.01-1.67)^{\star}$ \\
\hline PTSD symptoms (20.6\%) & $1.51(1.35-1.70)^{\star \star \star}$ & $1.48(1.20-1.83)^{\star \star \star}$ \\
\hline
\end{tabular}

${ }^{* * * P}<.000,{ }^{* * P}<.01,{ }^{*} \mathrm{P}<.05$ 


\section{Discussion}

The study found in a large sample of university students in low, middle income and emerging economy countries across Africa, Asia and the Americas a significant proportion of gambling participation, which was, however, probably lower than previously found in studies in high income countries (McComb \& Hanson, 2009; Mubaraka \& Blanksbya, 2013; Tozzi et al., 2013). The study found a large country variation in the proportion of gambling participation, with the highest frequent gambling (once a week or more) prevalence in South Africa, Barbados and Venezuela. Previous studies also found a high gambling participation rate among the adult population in South Africa (Collins \& Barr, 2009). In some study countries (China, Laos, Ivory Coast, Singapore) a low prevalence of gambling participation was found. Previous studies (Liu, Luo \& Hao, 2013; Loo, Raylu \& Oei, 2008) seem to show, however, a probably higher gambling participation among Chinese populations and among Singaporeans (Winslow, Subramaniam, Qiu \& Lee, 2010). Raylu and Oei (2004) suggest that there may be cultural differences in terms of being more vulnerable to begin gambling and to develop problem or pathological gambling, and that familial/genetic, sociological, and individual factors play a role in the development and maintenance of problem gambling.

The types of predominant gambling behaviours in this study (cards, numbers or bet on lotteries, slot machines, poker machines, other gambling machines, bet on sport, bingo, bowled, shoot pool, played golf, or played some other game of skill for money) was similar to what was found in previous studies (Burger et al., 2006; Engwall et al., 2004; Liu et al., 2013, McComb \& Hanson, 2009; Moore et al., 2013).

The preponderance of frequent gambling among male students as compared to female students has been largely found in previous studies (Gray 2004; Moore et al., 2013). Such gender differences may be attributed to men taking more risks and being more socially anxious than women, and greater risk-taking and more socially anxious individuals are more likely to have more problems with gambling (Wong, Zane, Saw \& Chan, 2013). In bivariate analysis, it was found that university students with a better economic family background were more likely involved in frequent gambling, as also found in another study (Winters et al., 1998). On the other hand, students from low or lower middle income countries were much more likely to engage in frequent gambling than students from higher middle income and high income countries.

In line with a number of previous studies (Engwall et al., 2004; Hodgins \& Racicot, 2013; Huang et al., 2007; Lorains et al., 2011; Sharp et al., 2014; Tozzi et al., 2013), this study found that several risk behaviours (having been in a physical fight, tobacco use, not always driving within the speed limit, sexual risk behaviour) were associated with frequent gambling. Likewise, poor mental health (depression and PTSD symptoms), as found in previous studies (Lorains et al., 2011; Moore et al., 2013; Sharp et al., 2014), was associated with frequent gambling in this university student population. In this study frequent gamblers experience high levels of other risk behaviours and other comorbid mental health disorders, which should be included in the development and delivery of prevention or intervention programmes for frequent gamblers or problem gambling among university students (Lorains et al., 2011; McComb \& Hanson, 2009).

\section{Limitations of the Study}

This study had several limitations. The study was cross-sectional, so causal conclusions cannot be drawn. The investigation was carried out with students from one or two universities in each country, and inclusion of other centres could have resulted in different results. University students are not representative of young adults in general, and gambling behaviour and its risk factors may be different in other sectors of the population. The assessment of gambling behaviour could have included the degree of problem or pathological gambling and other categories of gambling such as internet gambling, which have been found relevant in previous studies (McComb \& Hanson, 2009).

\section{Conclusion}

The study found, among a large sample of university students from 23 low, middle income and emerging economy countries across Asia, Africa and the Americas, a significant proportion of gambling participation. Several risk behaviours (having been in a physical fight, tobacco use, not always driving within the speed limit, sexual risk behaviour) and poor mental health (depression and PTSD symptoms) were identified, which may be utilized in interventions aiming at the reduction of frequent or problem gambling among university students. 


\section{Acknowledgements}

Partial funding for this study was provided by the South African Department of Higher Education. The following colleagues participated in this student health survey and contributed to data collection (locations of universities in parentheses) Bangladesh: Gias Uddin Ahsan (Dhaka); Barbados: T. Alafia Samuels (Bridgetown); Cameroon: Jacques Philippe Tsala Tsala (Yaounde); China: Tony Yung and Xiaoyan Xu (Hong Kong and Chengdu); Colombia: Carolina Mantilla (Pamplona); Grenada: Omowale Amuleru-Marshall (St. George); India: Krishna Mohan (Visakhapatnam); Ivory Coast: Issaka Tiembre (Abidjan); Jamaica: Caryl James (Kingston); Kyrgyzstan: Erkin M Mirrakhimov (Bishkek); Laos: Vanphanom Sychareun (Vientiane); Madagascar: Onya H Rahamefy (Antananarivo); Mauritius: Hemant Kumar Kassean (Réduit, Moka); Namibia: Pempelani Mufune (Windhoek); Nigeria: Solu Olowu (lle-lfe); Philippines: Alice Ferrer (Miagao); Russia: Alexander Gasparishvili (Moscow); Singapore: Mee Lian Wong (Singapore); South Africa: Tholene Sodi (Polokwane); Thailand: Tawatchai Apidechkul (Chiang Rai); Tunisia: Hajer Aounallah-Skhiri (Tunis); Turkey: Neslihan Keser Özcan (Istanbul); Venezuela: Yajaira M Bastardo (Caracas).

\section{References}

Andresen, E. M., Malmgren, J. A., Carter, W. B., \& Patrick, D. L. (1994). Screening for depression in well older adults: evaluation of a short form of the CES-D (Center for Epidemiologic Studies Depression Scale). American Journal of Preventive Medicine, 10(2), 77-84.

Babor, T. F., Higgins-Biddle, J. C., Saunders, J. B., \& Monteiro, M. (2001). AUDIT: The Alcohol Use Disorder Identification Test. Geneva, Switzerland: World Health Organization.

Binde, P. (2005). Gambling across cultures: mapping worldwide occurrence and learning from ethnographic comparison. International Gambling Studies, 5(1), 1-27.

Burger, T. D., Dahlgren, D., \& MacDonald, C. D. (2006). College students and gambling: An examination of gender differences in motivation for participation. College Student Journal, 40, 704-714.

Centers for Disease Control (CDC) (2013). The Global School and Health Survey background. Available from http://www.cdc.gov/gshs /background/index.htm at 15 April 2013.

Collins, P. \& Barr, G. (2009). Problem gambling in South Africa: A comparative report. Retrievd at http://www.responsiblegambling.co.za/ media/user/documents/NRGP\%20Comparative\%20Report\%20-\%20June\%202009.pdf, accessed 10 August 2014

Engwall, D., Hunter, R., \& Steinberg, M. (2004). Gambling and other risk behaviors on university campuses. Journal of American College Health, 52, 245-255.

Etel, C., Tabchi, S., Bou Khalil, R., Hlais, S., \& Richa, S. (2013). Prevalence of pathological gambling in Lebanese students. Encephale, 39(1), 1-5.

Gray, P. B. (2004). Evolutionary and cross-cultural perspectives on gambling. Journal of Gambling Studies, 20(4), 347-71.

Hodgins, D. C., \& Racicot, S. (2013). The link between drinking and gambling among undergraduate university students. Psychology of Addictive Behavior, 27(3), 885-92.

Huang, J-H., Jacobs, D. F., Derevensky, J. L., Gupta, R., \& Paskus, T. S. (2007). Gambling and health risk behaviors among U.S. college student-athletes: Findings from a national study. Journal of Adolescent Health, 40, 390-397.

Johansson, A., Grant, J. E., Kim, S. W., Odlaug, B. L., \& Götestam, K. G. (2009).Risk factors for problematic gambling: a critical literature review. Journal of Gambling Studies, 25(1), 67-92.

Kilbourne, A., Justice, A., Rollman, B., McGinnis, K., Rabeneck, L., Weissman, S., ... Rodriguez-Barradas, M. (2002). Clinical importance of HIV and depressive symptoms among veterans with HIV infection. Journal of General and Internal Medicine, 17(7), 512-520.

Kimerling, R., Ouimette, P., Prins, A., Nisco, P., Lawler, C., Cronkite, R., \& Moos, R. H. (2006). Brief report: Utility of a short screening scale for DSM-IV PTSD in primary care. Journal of General and Internal Medicine, 21, 65-67.

Lesieur, H. R., \& Blume, S. B. (1987). The South Oaks Gambling Screen (SOGS): a new instrument for the identification of pathological gamblers. American Journal of Psychiatry, 144, 1184-1188.

Loo, J. M., Raylu, N., \& Oei, T. P. (2008). Gambling among the Chinese: a comprehensive review. Clinical Psychology Review, 28(7), 1152-66.

Liu, L., Luo, T., \& Hao, W. (2013). Gambling problems in young people: experience from the Asian region. Current Opinion in Psychiatry, 26(4), 310-7.

Lorains, F. K., Cowlishaw, S., \& Thomas, S. A. (2011). Prevalence of comorbid disorders in problem and pathological gambling: systematic review and meta-analysis of population surveys. Addiction, 106(3), 490-8.

McComb, J. L., \& Hanson, W. E. (2009). Problem gambling on college campuses. NASPA Journal, 46(1), 1-29.

Moore, S. M., Thomas, A. C., Kalé, S., Spence, M., Zlatevska, N., Staiger, P. K., ...Kyrios, M. (2013). Problem gambling among international and domestic university students in Australia: who is at risk? Journal of Gambling Studies, 29(2), 217-30.

Mubaraka, A. R., \& Blanksbya, P. (2013). A study on problem and pathological gambling among university students in South Australia. Journal of Higher Education Policy and Management, 35(5), 471-482. 
Raylu, N., \& Oei, T. P. (2004). Role of culture in gambling and problem gambling. Clinical Psychology Review, 23(8), 1087-114.

Sharp, C., Dellis, A., Hofmeyr, A., Kincaid, H., \& Ross, D. (2014). First evidence of comorbidity of problem gambling and other psychiatric problems in a representative urban sample of South Africa. Journal of Gambling Studies, Jun 14. DOI 10.1007/s10899-014-9469-y

Tozzi, L., Akre, C., Fleury-Schubert, A., \& Suris, J. C. (2013). Gambling among youths in Switzerland and its association with other addictive behaviours. A population-based study. Swiss Medical Weekly, 143, w13768. doi: 10.4414/smw.2013.13768.

Wardle, J., \& Steptoe, A. (1991). The European Health and Behaviour Survey: rationale, methods and initial results from the United Kingdom. Social Science and Medicine, 33, 925-36.

Winslow, M., Subramaniam, M., Qiu, S., \& Lee, A. (2010). Socio-demographic profile and psychiatric comorbidity of subjects with pathological gambling. Annals of the Academy of Medicine Singapore, 39(2), 122-128.

Winters, K. C., Bengston, P., Dorr, D., \& Stinchfield, R. (1998). Prevalence and risk factors of problem gambling among college students. Psychology of Addictive Behaviors, 12, 127-135.

Wong, G., Zane, N., Saw, A., \& Chan, A. K. (2013). Examining gender differences for gambling engagement and gambling problems among emerging adults. Journal of Gambling Studies, 29(2), 171-89.

World Bank (2013). New Country Classifications, 2013. Available online: http://data.worldbank.org/ news/new-country-classifications (accessed on 5 April 2014).

World Health Organization (WHO) (1998). Guidelines for controlling and monitoring the tobacco epidemic. Geneva, Switzerland: WHO. 